\section{Zero crossing}

Helga Peter

Marburg, Deutschland

\section{Definition}

Nulldurchgänge wurden bei den Registrierungen mit Analogtechnologie als approximatives Verfahren zur Berechnung der Frequenz von oszillierenden Parametern benutzt.

\title{
Synonyme
}

Nulldurchgang 